\title{
PERSPECTIVA CONSTITUCIONAL DEL DERECHO A LA PROTECCION DE LA SALUD
}

\author{
Manuel María Zorrilla Ruiz \\ Catedrático de la Universidad de Deusto
}

\section{Garantías jurídicas del derecho a la protección de la salud}

La protección jurídica de la salud — plasmada en la generación de un Derecho objetivo que active el crecimiento de este bien de amplio espectro y alentador futuro- no se reduce al triunfalismo del Estado de obras que, cautivo de sus prejuicios típicos, heredó muchos de los objetivos tópicos del Estado autoritario. La eficiencia científica se invocó para justificar unos propósitos que, ajenos a esos fines de demostración, condicionaban la satisfacción de las nuevas necesidades de los grupos sociales. A la inercia - no todo lo fértil que era de desear- del Estado de obras, sucedió la idea de que el Derecho protector de la salud se explicaba en virtud del servicio al interés de las comunidades y -yendo más allá de las motivaciones inspiradas en el éxito de quién sabe qué filosofía política- encarnaba un compromiso predilecto del Estado social y democrático de Derecho y exigía el máximo de sus atenciones.

El nuevo sector del ordenamiento jurídico añade a la expresión social de los derechos individuales clásicos — como es, por excelencia, el derecho a la vida - otras variantes - tardías y de costosa aparición- que toman del signo de los tiempos su importancia y su legitimación sociopolítica. Resulta sintomático que, en éste y otros aspectos llamativos, los derechos sociales - de que es muestra emblemática el derecho a la protección de la salud - no sólo se caracterizan por el reconocimiento de las formas inéditas que los configuran, sino también porque, aunque su contenido esencial o núcleo inviolable pertenezca al de un derecho individual aceptado de antiguo, la demanda colectiva no se debe tanto a la conformidad con sus antecedentes históricos y su prosperidad actual, cuanto a la necesi- 
dad de prevenir los atentados contra sus aspectos más vulnerables y polémicos.

Los modos de ejercicio del derecho a la vida —investido de la más respetable dignidad axiológica - se ligan a los que la sicología llama actos reflejos y expresivos de una voluntad de vivir que, las menos de las veces, se muestra activa y perceptible, y, las más de ellas, aparece como algo difuminado y extenso. Se trata de un derecho especialmente afectado por los ejercicios de experimentación científica, bélica y/o sanitaria, que, so pretexto de productividad científica, impone la crudeza de los intereses políticos y económicos. Fenómeno que, como los hechos acreditan, desencadena aberraciones éticas y excita a la multiplicación de sus excesos.

La salud — protegida por el sector del ordenamiento jurídico que descubre y hace circular sus normas rectoras- es un bien o valor defendido por organizaciones que - entregadas a promoverlo en dosis y ambientes de cantidad y calidad variables - escenifican el tránsito - descrito por la sociología moderna- de una colectividad instintiva y espontánea a una comunidad reflexiva y consciente. Los grupos en que, según el art. 9.2 CE, se integra el individuo, son portadores de intereses cuya realización colectiva oscila entre el disfrute común de los más acuciantes y el goce selectivo de los obedientes a necesidades concretas. Tras el mérito que los arts. 9.2 y $20.3 \mathrm{CE}$ hacen del pluralismo de la sociedad y de lo variopinto de sus estructuras, el constituyente se refugia en el cap. $3 .^{\circ}$, tít. I CE para redefinir los intereses colectivos que animan el compromiso - constante en la cláusula transformadora y social- de alcanzar la plenitud de la libertad e igualdad efectivas.

La composición de los grupos sociales que postulan la protección de la salud, debe adecuarse a la dimensión antropocéntrica del medio y de las circunstancias en que sus reivindicaciones se formulan. El individuo es parte de comunidades intermedias - a cuya movilidad y traza no son ajenas aquellas reacciones- con el fin de recrear los valores de su ser personal y no de deprimirlos. Así lo da a entender el énfasis con que cuida de pronunciarse el art. 9.2 CE. Se descartan los objetivos maniqueos que, simulando designios de falsa protección, se diseñan para servir a un proyecto de eficiencia científica o contrastar la productividad administrativa que antepone a la dignidad de la persona — es decir, a la precisión de que el sujeto reciba cuanto merece, y no más ni menos del contenido de este crédito- el reparto mecanicista de las prestaciones sanitarias.

Tal antropocentrismo -inexcusable para entender el derecho a la protección de la salud y los avances de su regulación jurídica- urge al constituyente por encima de las licencias que le otorga la flexibilidad del decisionismo político. No faltan conceptos jurídicos - relativamen- 
te determinados-tolerantes con las manifestaciones del pluralismo político que — como subespecie de la libertad que, sumada a la igualdad, se sintetiza en la justicia- propugna el art. 1.1 CE. Ahora bien, la vida en dignidad - trasluz de la cosmoeminencia o dominio razonable de la persona humana sobre el resto de los seres, animados o no, que pueblan el mundo- se explica por la valiosa dimensión de los derechos que, incluido el relativo a la protección a la salud, se conectan mediante los arts. 10.1 y $43.1 \mathrm{CE}$. Esta rotunda reflexión prohíbe utilizar las normas de Derecho objetivo o ejercitar los derechos subjetivos en nombre de intereses generales cuyo parentesco con la razón de Estado o la voluntad política les destituye del sano concepto de interés social. Situación que se advierte en los estímulos que un grupo - notoriamente implantado en el interior de las realidades sociales y dotado de arraigo- ejerce cuando defiende solidariamente los derechos que convienen a la totalidad y la singularidad de sus miembros. El hecho de que, como rezan los arts. 28.2 y $37.2 \mathrm{CE}$, las prestaciones públicas de protección de la salud se denominen servicios esenciales de la comunidad, no deprime el significado de los valores personales y representa la medida de apoyo que enaltece el rango del derecho a la vida y la integridad física de la persona individual.

\section{Particularidad sistemática del art. 43.1 CE}

No puede tacharse de retórica la iniciativa con que el constituyente ha situado los contenidos del cap. $3 .^{\circ}$, tít. I CE bajo la rúbrica De los principios rectores de la política social y económica. Esta opción sistemática no admite compartimentos estancos ni aspectos divisibles de una y otra política, sino que pertenece a un discurso integrador de materias participadas por ambas.

La expresión política social no conserva el alcance a que se ha recurrido para designar el servicio público atento a las necesidades de la nueva clase - el estamento de los trabajadores dependientes- cuya emergencia provocó, en la segunda mitad del siglo XIX, la disolución del utópico monismo social y la iniciación del proceso que desembocaría en el pluralismo de la sociedad. Los sistemas autoritarios patrocinaron un concepto de política social que enfrentaba lo atrevido de su compromiso - inédito hasta entonces - a una neutralidad que se consideraba censurable y perversa. Ni más ni menos que aquella con que, tras despenalizar la tutela de la paz productiva y acentuar su indiferencia social, el Estado de Derecho liberal burgués transfirió a los empleadores una carga - la de soportar, como uno de los riesgos de su aventu- 
ra industrial, las consecuencias de la creciente conflictividad- cuyo ejercicio aceleró la desocialización de las relaciones de trabajo.

La política social europea -incorporada hoy al tít. XI VCTRha sido el resultado, muy parco en su voluntad superadora, de aproximar - es decir, de alinear, marcando el paso- las políticas sociales nacionales que, para mayor lastre de sus aspiraciones de progreso, se sustrajeron al control jurisdiccional en el marco de la supralegalidad comunitaria.

El legislador constituyente confiere a la política social un amplio espectro que incluye el derecho a la protección de la salud de las personas físicas de las comunidades más diversas. Sorprende que un pasaje dedicado a la formulación de principios acoja, de modo extravagante, el reconocimiento del derecho que formula el art. 43.1 CE. El art. 44 CE registra una diversión semejante respecto al derecho a la cultura. Cierto que, si se atiende a la colocación del art. 35.1 CE bajo el rótulo De los derechos y deberes de los ciudadanos, los trabajadores dependientes forman un grupo significativo de la sociedad, pero, si la idea de política social se ciñe a dicho círculo, se está negando la existencia relevante de otros ámbitos en que, como el art. 9.2 CE ha señalado, figuran las personas situadas - giro de nuevo cuño existencial- y se ignora la complejidad del tejido social que - no menos acusadamente por el hecho de hacerlo de pasada- el art. 20.3 CE pone al descubierto. La política social es, desde esta atalaya, la racionalización de las medidas que los poderes públicos adoptan para promover la igualdad y la libertad - factores decisivos de la posesión del bienestar - de unos grupos sociales que, según el criterio empleado para definirlos, ordenan sus medios personales y reales a la mayor eficiencia de los fines que justifican su razón de ser. Han surgido merced a una conciencia de identidad que, percibida sin error, expande sus valores explícitos, intuye la necesidad de acciones colectivas y alcanza un grado de organización eficaz.

La política social también se asocia al esfuerzo transformador que elimina cuantos obstáculos frenen la libertad y pluralidad de los grupos, y no sólo del - más amplio y consistente- que la clase trabajadora compone. Las colectividades que abanderan demandas de protección de la salud, son acreedoras al tratamiento de una política social acorde con las aspiraciones que, en cada caso, manifiestan. Sin ser privativa de los trabajadores dependientes, esta suerte de protección les beneficia, dada su condición de habitantes estadísticamente mayoritarios de cada uno de los círculos a que la oferta del constituyente se dirige.

La política económica se acomoda a las pautas que - fijadas en el tít. VII CE - informan la acción de los poderes públicos competentes 
para desarrollarla. Basta advertir cómo los arts. 128 a $131 \mathrm{CE}$ sientan orientaciones — dependientes de la ductilidad del decisionismo oficial- que, ante la movilidad facilitada por el valor superior del pluralismo político en el art. 1.1 CE, permitían preferir criterios económicos dirigistas o liberalizadores. La opción se ha concentrado desde que, en virtud del principio de primacía del Derecho Comunitario, el signo peculiar de este ordenamiento - engrosado con la cesión de competencias que autoriza el art. $93 \mathrm{CE}$ - proscribe cualquier variante de intervencionismo irrazonable contra los básicos derechos de libertad de establecimiento y libre circulación de capitales.

¿Qué anuncia el rótulo elegido para encabezar el cap. $3 .^{\circ}$, tít. I CE y dar en él entrada al derecho a la protección de la salud? No quiere decirse que una parte de los principios enunciados afecta a la política social y que la otra concierne a la política económica, ni tampoco pretende escindirse un cuerpo común en dos bloques de regulación. Se intenta construir una ordenación unitaria e interaccionada que haga suyas ambas cualidades.

Los criterios gramatical y sistemático de interpretación de ese pasaje constitucional muestran que las medidas anunciadas entonces y encomendadas a los poderes públicos, pertenecen — simultánea e indivisiblemente- a sendos marcos de la política social y la política económica. Mientras que el contenido social de los principios enunciados se desprende del tenor literal de sus proposiciones, el impacto económico — que no se ha explicitado - resulta de la inequívoca intencionalidad nominativa de su encabezamiento.

La prioridad otorgada por el constituyente a los objetivos sociales que acampan en el cap. $3 .^{\circ}$, tít. I CE, depende — pues tal es la razón de que el mismo cuide de apropiarse el término política económica- del notable coste financiero de unos recursos materiales — destinados a satisfacer aquellos fines - cuya asignación y obtención no pueden soportar los impedimentos que se hacen valer comúnmente. No cabe oponer objeciones o trabas que, como las que invocan la reducción o redistribución del gasto público, se aferran a una orientación - la del monetarismo a ultranza - reñida con el sistema de valores que el art. 1.1 CE predica del Estado social y democrático de Derecho.

Las consignas del cap. 3. ${ }^{\circ}$, tít. I CE se encaminan a todo lo contrario de lo que aconsejarían las versiones de una tentativa de interpretación económica del Derecho. Ningún prejuicio material puede anteponerse a la urgencia de desarrollar - dentro de un plazo que no suscite el reproche de inconstitucionalidad por omisión- los principios allí formulados. La planificación programática del art. 53.3 CE veda los paliativos o disculpas que, justificando la mora legislativa, priven de la dosis de le- 
galidad que el ordenamiento jurídico demanda para proteger los intereses de los ciudadanos que se aprovechan de ese desarrollo.

Tal es la conclusión acorde con los imperativos eticosociales que el constituyente ha observado al amparo del bloque de moralidad legaliza$d a$ que canoniza el art. 1.1 CE. Su cumplimiento —incluida la visión del art. 43.1 CE y el resto de los principios que los arts. 45.1 y $51.1 \mathrm{CE}$ conectan con el derecho a la protección a la salud - tiende a conseguir los óptimos frutos del avance de la cláusula transformadora y social del art. 9.2 CE. Importa la exigencia — moral y jurídica — de que ningún obstáculo de naturaleza económica entorpezca la consecución de sus fines. He ahí la grandeza y servidumbre del espacio social erigido por el constituyente para habitar la tierra prometida del porvenir solidario que augura. Ello, con preferencia a opciones que puedan desocializar el proyecto, pues la elasticidad del decisionismo político dificulta el control de otras soluciones que hipotequen la magnitud de esas finalidades.

La rotulación del cap. $3 .^{\circ}$, tít. I CE carecería de sentido en otro caso, pues, aunque omite medidas específicas de política económica, el tenor de su rúbrica no es indiferente e inspira - de modo inmediatoel carácter de las determinaciones adoptadas para realizar sus principios. La justificación de que - pese al silencio de los arts. 39 a 52 CE sobre conceptos de política económica- sus directrices no se desentienden de este aspecto, se condice con la literalidad del cap. $3 .^{\circ}$, tít. I $\mathrm{CE}$, se explica por la voluntad presunta del constituyente y exige concluir que - si no se desvirtúa la etiqueta de su encabezamiento- el mensaje social de cada una de aquéllas obliga a las acciones complementarias de una política económica que no puede rehusar a las medidas de política social el auxilio que ésta espera y exige.

El razonamiento se predica, por derecho propio, de la regla que el art. 43.1 CE dedica al derecho a la protección de la salud.

$\mathrm{El}$ art. 9.2 CE obliga a los poderes públicos a remover las dificultades que frenan el proceso de liberación - pues así se cumplen las aspiraciones del cap. $3 .^{\circ}$, tít. I CE- de los grupos sociales a que, en general, concierne su vasto proyecto, $y$, en particular, de los interesados en ver satisfechos de los derechos cuya perspectiva constitucional se considera.

\section{Contenido esencial del derecho a la protección de la salud}

Se usa del término salud para designar un concepto jurídico indeterminado cuya definición parece imprescindible. No se ignora lo enigmático de que - aun cuando el art. 43.1 CE extravaga del cap. 2. ${ }^{\circ}$, tít. I CEel derecho a la protección de la salud conserve la apariencia de un crédito 
del ciudadano frente al Estado o derecho-facultad que se encuentra bajo la rúbrica De los principios rectores de la política social y económica. Lo inevitable de su descripción y desarrollo normativos - recordados en el art. 53.3 CE a un legislador ordinario que no puede demorar indefinidamente el compromiso que le incumbe- enfrenta con las alternativas propuestas para describir un contenido esencial o acervo de intereses resistentes a cualesquiera acciones erosivas.

Una de esas teorías relaciona el léxico empleado - el término salud de que se sirve textualmente la legalidad fundamental- con el metalenguaje o idea familiar a que, para individualizar la noción, acuden los aplicadores del Derecho. El desarrollo positivo del principio constitucional hace comprensible el perfil existencial del tipo abstracto del derecho que, andando el tiempo, se asimila por la conciencia común y las intuiciones culturales. No es ésta la construcción más conveniente a la delicadeza del tema que se aborda, pues la evolución y las tensiones dialécticas de la definición de la salud, generan otras aspiraciones que animan los ensayos protectores del Derecho de la postmodernidad. Sin romper con el testimonio y los hallazgos del pasado, hay que reconocer lo módico y escueto de los postulados que se reconsideran. Reducir a esos límites lo que el art. 43.1 CE entiende por salud, es minimizar la dosis de interés legítimo que el modelo del derecho subjetivo ha de apropiarse para merecer la tutela del legislador. Ha de evitarse la disociación entre las condiciones internas de la sociedad democrática —que incluyen la búsqueda de una existencia saludable - y los ecos o disfunciones culturales a que hay que dar de lado para que, superando las insuficiencias del concepto de salud, se afronte con éxito su dimensión renovadora.

La otra vía de concretar el contenido esencial del derecho consiste en traer a la vista el bloque de intereses comúnmente aceptados como base del derecho constitucional cuyas manifestaciones se intenta averiguar. De ahí, que su vulneración se aprecie cuantas veces median restricciones que priven a la norma jurídica — definidora y/o continente del derechode valor vital o aptitud estadística para preservar sus rasgos de generalidad, desvinculen su mensaje de los intereses generales a que debe servir, reduzcan su eficacia más allá de lo razonable o dejen desarmado al derecho frente a las agresiones del medio en que ha de ejercitarse.

Aunque ambas vías se correlacionan y completan, queda en pie la cuestión de su validez metodológica para determinar el contenido esencial del derecho a la protección de la salud. La descripción que facilita la primera, ofrece los inconvenientes del empequeñecimiento conceptual y la escasa fuerza de significación. Cuando, sin prescindir de su contribución, se acude a la segunda con la confianza puesta en las reve- 
laciones de los signos de los tiempos, las probabilidades de acierto de la operación emprendida se multiplican.

Si todo interés entraña una apetencia por los bienes sensibles de la vida, es obvio que los intereses garantizadores del derecho a la protección de la salud dependen de la voluntad y envergadura del proyecto deseado por la sociedad democrática avanzada que predice la dec. 5 Pr.CE. Sin asentir a una noción monolítica y cerrada de lo que representa este avance, se apuesta por la coexistencia de una salud entendida normativamente - conforme a los hábitos de una cierta conducta de vida- y una salud ordenada descriptivamente, según un proyecto racionalizado de bienestar individual y colectivo. La sugestiva regla del análisis transaccional -yo estoy bien, tú estás bien-corrobora ingeniosamente esta idea y exhuma el afán de coordinar las nociones clásicas - sobremanera respetables - de lo que la salud y su tutela han sido, con la novedad de las soluciones pensadas para disolver las fricciones antisaludables que surgen en el seno del conflicto social.

Esta elección metodológica parece preferible y permite definir la salud mediante el análisis de las fases que convienen a la salud básica, la preservación de la salud y la autorrealización de la persona.

Sin ignorar las censuras debidas al empleo de unas vías que adolecen de simplificaciones a la hora de fijar el contenido esencial del derecho a la protección de la salud, el sincretismo del método propuesto no está exento de algunas ventajas. Pese a su exceso de sociologismo y su insuficiencia filosófica, rinde un sano servicio a la tarea del legislador ordinario, cuyas iniciativas facilita, y a los aplicadores del Derecho - especialmente a los órganos de la jurisdicción - que cuentan con un instrumental susceptible de utilización inteligente y tempestiva.

A nadie se oculta la importancia que la determinación y el crecimiento del contenido esencial de los derechos constitucionales adquieren para despertar y enriquecer la actitud que lleva el nombre de sentimiento constitucional. Su incidencia en la esfera del derecho a la protección de la salud no es una excepción y obliga a analizar los modos adecuados de efectuar esas operaciones.

La suerte del derecho a la protección de la salud debe precaverse contra los peligros de que el legislador ordinario - sordo a las demandas del interés general o ignorante de sus peticiones más urgentes- le prive de valor vital y convierta sus normas en un instrumento inútil para lograr los fines a que se asocia su regulación. Hay una tesis de proporciones medias - defensora de que el contenido esencial del derecho a la protección de la salud se exponga a colisiones con otros intereses en pugna- - y una posición maximalista que le concibe como una magnitud irreductible y absoluta. 
El derecho a la protección de la salud contiene un elemento material o garantía de que - a cambio de respetarse las preferencias ideológicas de la intervención legislativa- no ha de verse anormalmente deprimido ni privado de los mínimos de utilidad y apetencia sensible que justifican su reconocimiento constitucional. El respeto a la dignidad personal —que, según el art. 10.1 CE, imprime carácter al ejercicio ponderado de los derechos y las libertades- está en la base de este ingrediente indispensable. La amplitud del contenido esencial sólo se puede restringir si el concurso de otros intereses - temporales y preponderantes- exigen una elección que deje a salvo el menos lesivo para la supervivencia del núcleo afectado.

La cuestión - conexa con el tema de una indagación sobre la esencia- requiere aproximarse a sus presupuestos filosoficojurídicos, controlar las variables politicoculturales que pueblan el campo del derecho en cuestión, entender las evaluaciones antropocéntricas del ordenamiento constitucional y superar las tentaciones tautológicas que - explotando la naturaleza de ciencia del espíritu que asiste al Derecho en la solución de los problemas que afronta- dan entrada en las definiciones a lo que cabalmente quiere definirse.

Sin perjuicio de las fórmulas - ya consideradas - que permiten a los aplicadores del Derecho objetivo protector de la salud definir el contenido esencial del derecho subjetivo a su tutela, dicho núcleo inviolable se intuye en las brumas de algunas tensiones. La intangibilidad del individuo prevalece, porque el desarrollo de la personalidad - tenazmente aludido en los arts. 10.1, 25.2, 27.2 y 45.1 CE- depende de integrar armónicamente cuantos elementos contribuyen a la perfección e inteligibilidad del concepto de salud. La autorrealización condiciona el ejercicio de muchos de los derechos fundamentales que, en su defecto, se achican y reducen a una titularidad huérfana de sus elementales opciones de ejercicio. La máxima — solidariamente acatada por las corrientes de la teología, la sociología y la sicología profundas- de que quien no vive, no se redime ni existe dignamente, muestra cómo esa plenitud es parte irrenunciable de las situaciones de bienestar preconizadas en el Pr.CE y confirmadas por el compromiso que el art. 9.2 CE estampa en su cláusula transformadora y social.

\section{Aspectos de la naturaleza jurídica del derecho a la protección de la salud}

Invocar el derecho a la protección de la salud - persiguiendo una existencia saludable y coincidente con las aspiraciones particulares del 
sujeto- es ignorar que las técnicas especializadas —laboriosamente conseguidas e indispensables para la conservación colectiva de la salud misma - no se rigen por las normas deontológicas del mundo del deber ser o del valor, sino por las reglas cosmológicas del mundo del ser o de la naturaleza causal. Son propias de éstas, la sencillez de sus proposiciones, la sujeción al automatismo de los acontecimientos naturales y la percepción sensorial de su contenido fenoménico. Lo contrario, pues, del enunciado reflexivo, el carácter alternativo de la decisión intelectual y la dificultad de atribuir un origen inconfundible a los efectos de las normas del mundo del valor. La protección de la salud proviene de cumplir las prestaciones positivas que - puestas a cargo de los poderes públicos - consisten en desarrollar, mediante obligaciones de atención y cuidado, los esfuerzos precisos para que la persona entre en posesión del óptimo de recursos saludables a que es acreedora. Ello suscita la cuestión de si los procedimientos eficaces — que el art. 51.1 CE garantiza en pro de la salud de los consumidores - no exigen cumplir de inmediato ese deber de diligencia y, en el caso de su vulneración, imputar al Estado las consecuencias indemnizatorias del daño sufrido.

El concepto de derecho protector de la salud depende de una valoración colectiva que - superando el individualismo que le confinó en el marco del derecho a la vida - trasluce las aspiraciones de una política social que opera en campos tan extensos como indiscutibles. Así se explica que el ejercicio del esfuerzo transformador de los poderes públicos — sintetizador de la libertad e igualdad efectivas- asegure el pleno desarrollo de la personalidad que, según el art. $28 \mathrm{CE}$, contribuye a colmar esos fines. Ello se infiere de la disciplina del cap. $3 .^{\circ}$, tít. I $\mathrm{CE}$, donde - bajo la repetida rúbrica De los principios rectores de la política social y económica - el art. 43.1 CE sirve a intereses que, satisfechos con criterios de política social, imponen requerimientos de política económica que, lejos de coartar la consecución de los primeros, han de atenderse con una preferencia que no enturbie la transparencia de sus valores ni frustre su efectividad.

Gracias a los mecanismos que técnicamente garantizan la protección de la salud, las personas físicas son titulares de un derecho social - cuyo crédito se satisface mediante la deuda tutelar de los poderes públicos o los particulares que realizan las prestaciones obligatorias oportunas - y de un derecho de libertad que, además de condenar los atentados contra el decisionismo individual, incluye el deber cooperativo de defender la salud pública y soportar determinadas restricciones. Los poderes públicos son los administradores eficaces de un haz de relaciones sociales que - como elementos de esa promoción saludableacrecientan el progreso material y moral de los ciudadanos. 
Sorprende que el art. 43.1 CE se ocupe de la protección de la salud en un pasaje cuya finalidad no es la de reconocer derechos innatos preexistentes y sí la de enunciar principios de acción destinados, como indica el art. 53.3 CE, a la suerte del desarrollo legislativo ordinario. El reparo interpretativo puede superarse admitiendo que el constituyente - concesivo, a veces, con las tentaciones de permisividad semánticausa también aquí de una licencia literaria. Acaso carezca de sentido reconocer ese derecho subjetivo fuera de las secs. $1 .^{\mathrm{a}}$ y $2 .^{\mathrm{a}}$, cap. $2 .^{\circ}$, tít. I $\mathrm{CE}$, en que debió insertarse con la eficacia preceptiva directa que sanciona el art. 53.1 CE. Parece inconsecuente situarle - como tal derecho- bajo el rótulo que se reserva a los principios. La apertura de un debate sobre el particular - pretendiendo optar por uno u otro de los niveles protectores del art. 53.1 y $3 \mathrm{CE}$ - plantearía el descubrimiento de una tierra de nadie o, al menos, de una zona gris de difícil esclarecimiento.

Aun cuando su formulación se reduce a la eficacia diferida de un principio garantizado en pro de los grupos sociales, el derecho a la protección de la salud - expresivo del contenido esencial o núcleo invulnerable del derecho a la vida y a la integridad física - ha puesto a los arts. 15 y $43.1 \mathrm{CE}$ en una relación de complementariedad incontestable. Nadie niega que el modelo acogido a la rúbrica Derechos y libertades, en el cap. $2 .^{\circ}$, tít. I CE, se origina - con una intensidad dependiente de la capacidad comprensiva y asimiladora del sentir común - en el molde de unos derechos naturales que la tradición y el contexto cultural declaran inalienables. Parece poco lúcido entender que los principios rectores de la política social y económica — sin exceptuar el que, bajo la laxa denominación de derecho, aloja el art. 43.1 CE - se reducen al germen o proyecto inmaduro de otros derechos sustancialmente distintos de los ya reconocidos, y que, sin atisbarse aún en el horizonte histórico de la razón práctica, están a la espera de su definitiva recepción y refrendo. La traza del derecho a la protección de la salud y de los principios que sistemáticamente conviven con él, prueba que sus signos de identidad o referencias-clave conciernen a situaciones reconocibles en el medio cultural al que se destinan. Nada tan lejos de la realidad y los usos sociales como el defender que esos principios gozan de una naturaleza inédita y extraña al espacio ocupado de antiguo por unos derechos y libertades de los que, quiérase o no, siguen siendo una expresión imprescindible y provechosa.

El bloque de principios que enuncian los arts. 39 a $52 \mathrm{CE}$, abarca los aspectos notables - tratados como intereses difusos- del contenido esencial de unos derechos y libertades que, en cuanto preexistentes, el legislador fundamental acata y hace suyos. El constituyente no ha es- 
perado a la intervención del legislador ordinario para proveer a ciertos aspectos de su definición y pormenores. El contenido esencial exige respetar la materia reservada a la ley por el art. 53.1 CE, pero también admite - como evidencia la lectura del cap. $3 .^{\circ}$, tít. I CE- el adelanto, entre otras manifestaciones, del reconocimiento del derecho a la protección de la salud.

La situación se asemeja a la que surgiría si algunas particularidades del desarrollo inmediato de los derechos y libertades constitucionales, se transfiriesen a un pasaje autónomo que, acogiéndolos en forma de principios, proclamase su atención preferente $\mathrm{y}$, a despecho de objeciones economicistas, obligase a plasmarlos en normas jurídicas eficaces. Hay una suerte de elasticidad intraconstitucional, por la que todos los principios - no preceptos - del cap. 3. ${ }^{\circ}$, tít. I CE tienden a evadirse de sus compartimentos actuales y retornar a las normas declarativas de unos derechos y deberes básicos a cuyo núcleo invulnerable pertenecen con independencia del enclave sistemático que se les asigna.

El principio innovador del derecho a la protección de la salud es un extremo - sustancialmente conexo y contextualmente alejadodel reconocimiento de los derechos a la vida y a la integridad física que figuran en el art. $15 \mathrm{CE}$. Traza la vía conducente a que, en los óptimos niveles del derecho fundamental, la vida gane en duración, mejore en calidad y alcance los modos de realización más dignos y esperanzadores.

\section{Concepto comprensivo y progresivo de salud}

La enfermedad y la salud se interaccionan en virtud de un protagonismo antagónico que trae a la memoria la lucha maniquea con que los principios del bien y del mal se disputan el dominio de la libertad de la persona. Para determinar el contenido esencial del derecho que reconoce el art. 43.1 CE, ha de advertirse que - excepción hecha de las inercias autodestructivas causadas por una elección infortunada del arte de vivir - todo individuo propende a mejorar por obra de su instinto bondadoso de conservación y progreso, mientras que las reacciones - no siempre previsibles ni evitables- del mundo circundante dan entrada a componentes agresivos que debilitan y/o sofocan los esfuerzos positivos de la razón vital. El óptimo de estado saludable pretende reflejar, ni más ni menos, que el imperio adquirido por esa razón a través del equilibrio individual y el proceso consiguiente de autorrealización. 
El contenido esencial del derecho a la protección de la salud presupone que - no obstante los vínculos complementarios que unen a la sociedad pluralista con las personas físicas que militan en sus grupos- la persona y la sociedad entran en fricción con más frecuencia de la que sería deseable e incluso de la conveniente para la prosperidad de sus contactos. Los componentes o factores sociales - variables de la ecuación que describe la estructura de la sociedad y exhuma sus mudanzas - prueban la intervención de fuerzas que, quién sabe con qué orígenes y finalidades, hacen peligrar el proyecto existencial de cada uno y arruinan sus expectativas. Los grupos sociales - llamados a contribuir a las tareas de la perfección individual y a no frustrar los valores de su espontaneidad - sufren procesos deformadores que les privan de su condición de coadyuvantes a la causa de la dignidad personal y, a veces, les convierten en sus más encarnizados adversarios. Cualquier proyecto integrador - en lo que tiene de seriamente antropocéntrico y accesible al resto de la comunidad- se resiente de las claudicaciones debidas a los episodios de miseria moral que le abruman y, en ocasiones, secuestran de por vida.

Lo que, en sus fuentes, fue un proceso armonizador del papel de los grupos sociales respecto a las individualidades que los integraban, deviene un cúmulo de realidades que, a la larga, definen un estado de conflicto entre el ser personal - que asigna a las comunidades un sentido y función cuya nobleza va desmereciendo-y las consecuencias negativas de esa perversión.

El dilema salud-enfermedad se suscita a partir de lo evidente del conflicto compartido por cuantas personas y grupos corren la aventura de sobrevivir o perecer. El inventario de los ataques del medio social - que, para mal, no siempre representa la circunstancia complementaria del yo personal - debilita la condición de ser desfalleciente que acompaña a la persona caída en este mundo, y se culmina con el triunfo de la sociedad agresiva - que la degrada y la transforma en un enfermo- o con la victoria de quienes, impulsados por su salud básica y agotando los recursos de su reserva de salud, prosiguen la marcha emprendida en pos de su autorrealización. Así se explica la necesidad de superar la estrechez del concepto normativo de salud y de adiestrarse en la configuración doctrinal de un concepto positivo que explique lo que son y significan la salud básica, la reserva de salud y la autorrealización.

La salud básica consiste en una ausencia de mal que sólo se percibe cuando sufre los embates de la enfermedad que incide en ella para destruirla. Es axiomática la idea de que o se tiene salud básica o se carece de ella. 
La reserva de salud equivale a un contingente de bienes sicofísicos que habilitan para resistir el asedio de la enfermedad y los atisbos de la pérdida de la voluntad y la fatiga. Es claro que, siquiera en medida variable, con la reserva de salud se cuenta siempre.

La autorrealización - perfeccionada con la plenitud del equilibrio personal - revela la solidez de una existencia autónoma que, a diferencia de la reserva de salud, puede o no haberse logrado. La autorrealización comprende la consciencia del bienestar físico de que se disfruta, la adquisición y posesión razonable de bienes materiales, la morigeración de la avidez desordenada, la constancia del equilibrio interior y de la estabilidad del humor, el desarrollo de las actividades elegidas y la gratificación de los contactos con el entorno personal y social. La autorrealización trasluce meridianamente la planificación de la - siempre discreta-libertad mundana del sujeto. Se accede al equilibrio cuando ninguna tensión anormal coarta la libertad de decisión con que el entendimiento y la voluntad distribuyen racionalmente el uso de sus energías.

La autorrealización es una referencia empíricamente normativa e independiente de las circunstancias del tiempo y del lugar en que se advierte, promueve y acrecienta. Su adquisición descansa en la premisa de que cada persona es dueña de una naturaleza esencialmente biológica que, en parte, le pertenece y, en parte, corresponde al acervo común de la especie humana. Su hallazgo prueba su bondad intrínseca o, al menos, su neutralidad, y aconseja elevarla a principio rector de la vida. $\mathrm{Si}$, a causa de las compulsiones interiores o la presión de los hechos externos, la naturaleza decae y se empobrece, la persona - cuya capacidad de resistencia acusa esa derrota- pierde sus oportunidades de equilibrio y se ve invadida por la enfermedad que le oprime. Lo paradójico de la naturaleza —optimistamente rescatada frente a la pesimista idea de la convivencia antisocial - es que, aunque se expone a frecuentes escaramuzas y deméritos, se regenera y lucha infatigablemente para repeler las agresiones, y no desiste de su afán de hacerse perceptible e influir en cuanto le rodea.

La realidad - de cuyo conocimiento y esfuerzo dominante depende la planificación del equilibrio personal - no sólo se aprecia mediante las operaciones sensoriales que le acercan al conocimiento subjetivo, sino que también se interpreta y presiente gracias al ejercicio de las aptitudes superiores. La persona es consciente de que su existencia - buena para dotar a sus opciones de la efectividad y lucidez que reclaman - apareja riesgos de flaqueza que debe conjurar. Su autoconciencia se fortifica a la medida que, más allá del pienso luego existo, se sensibiliza a las prevenciones y advertencias consecuentes con la constancia de aquel dato. 
La persona toma razón de que la suma de incentivos que pueblan su interior y son la clave de su existencia ilusionada y ambiciosa, se expone al influjo de acciones exteriores y determinantes de una disposición que - desafiando a los estímulos estéticos- enriquece sus capacidades. No ignora que las acciones hostiles de la naturaleza se ponderan en función de su inercia - a veces imparable-y de la ausencia de intencionalidad que las caracteriza. El cultivo de la espontaneidad - que la virtud de la prudencia obliga a moderar para no incurrir en censurables excesos- constituye una necesidad física cuya satisfacción, si es tempestiva, nada tiene que ver con las demasías del desorden síquico o la apetencia irrefrenable.

La aceptación de sí misma, del entorno — sicológico y social— de la persona y de sus aledaños cosmológicos, es omnicomprensiva y ratifica la exigencia que - al descubrir la verdad de la teoría - prohíbe al individuo desentenderse de la realidad y le conmina a explicarla en todas y cada una de sus manifestaciones. Esta dependencia relativa no inhibe y sí fomenta la libertad personal, pues despierta un sentimiento de sustantividad especialmente intenso y un urgente deseo de preservar los reductos de la intimidad. Sumida en este medio, la persona provista de salud acata la necesidad de actuar en la esfera de su autonomía, de razonar y elegir cuantas veces lo aconseja el ejercicio de su entendimiento, y de reaccionar frente a las tentativas de imponerle una cosmovisión — sofocante y dogmática- que anula sus más caras aspiraciones críticas.

La adquisición del nivel de madurez adecuado a la plenitud saludable, despierta actitudes de asombro ante fenómenos que provocan reacciones del siquismo personal, especialmente si los incentivos emocionales reclaman respuestas de mejora y progreso. Sin perjuicio de esta totalización optimista, la autorrealización transmite a la existencia individual un elenco de experiencias que se autoseleccionan insensiblemente y dan lugar a que las vivencias superiores preponderen sobre las de signo inferior y las desplacen.

La persona saludable se cerciora de que, gracias a este encadenamiento, su condición existencial - regenerada en ella y en sus semejantes - anima su sistema de curiosidades, le induce a especular sobre su magnitud y, lejos de abrumarla, le identifica con el cúmulo de problemas de la familia humana. La salud es disponibilidad para no decaer en la conquista de los espacios de la comunidad que la persona se esfuerza en ocupar al consumar sus proyectos y reconstituir sus expectativas.

Si la persona saludable asume riesgos que, no obstante lo recio de su vigor vital, afectan a su posición relativizada y conexa con la de 
otras existencias, la estabilización de sus valores -independencia, protección de la intimidad, defensa de la autonomía y resistencia al dogmatismo - revela un carácter receptivo y susceptible del enriquecimiento que van a procurarle otros ascendientes e influencias.

El proceso de autorrealización es incompleto si la persona no tiene la osadía de cuestionar y modificar, llegado el caso, la disposición de la escala de valores en que inciden aquellas peripecias. Quienes aciertan en la recolección de estas cualidades y se acomodan a sus requerimientos, alcanzan, más tarde o más temprano, el grado de autorrealización conveniente a la plenitud de la salud que tienen derecho a obtener.

Estos modos de definir el contenido esencial del derecho reconocido, bajo apariencia de principio, en el art. 43.1 CE, responden a la idea de que la igualdad - fundamento de las cotas de la libertad accesible y nunca elemento restrictivo de sus expansiones- es inseparable del mensaje que ha puesto en circulación el concepto modernizante de salud. La dignidad personal se disipa y anula si - a través del proceso que acaba de exponerse - el proyecto del art. 10.1 CE defrauda las aspiraciones adecuadas a la posesión de estado saludable.

¿Cuál es la relación apreciable entre los componentes de la salud que así se esboza?

Puede afirmarse que, en punto al contenido, la salud básica sólo es, ya que consiste en la ausencia de enfermedad y carece de elementos tangibles, mientras que la reserva de salud se posee y la autorrealización se colma y se consigue.

Si se atiende a la vinculación al individuo, la salud básica es un hecho o vicisitud explicable por el dilema del todo o la nada, mientras que la reserva de salud incluye un riesgo de dimensión variable y objeto de una directa toma de conciencia. La autorrealización se debe a una norma de conducta personal que desencadena esa toma de conciencia inmediata. La salud básica constituye la premisa de la reserva de salud en que descansan las opciones de la autorrealización.

En vista de sus relaciones con la enfermedad, la salud básica queda destruida por ésta, la reserva de salud ejercita su capacidad de resistencia para combatir la acción agresiva que padece, y la autorrealización suprime las expresiones patológicas en que la acción de la enfermedad se ha traducido.

Desde una perspectiva orgánica, la salud es un estado corporal, no absoluto, que se compone de la ausencia de enfermedad y de la capacidad refleja de rechazar sus ofensivas. La salud se define conductivamente como el modo de relación preferible entre la persona — realizada merced a su pleno equilibrio- y el medio en que se despliega su existencia de presente y se preordenan sus expectativas de futuro. 
Así se adviene a una plausible conclusión sobre lo que el contenido esencial o núcleo invulnerable del derecho a la protección a la salud implica en la cláusula de reconocimiento que el art. 43.1 CE le ha dedicado.

\section{Salud y vida humana en formación}

La interrupción de la vida en formación es uno de los aspectos más polémicos del derecho a la protección de la salud. Los legisladores no silencian los prejuicios demagógicos que, con base en la densidad de las informaciones estadísticas, eluden el discurso de la sociología jurídica y las condiciones axiológicas de las medidas que adoptan al respecto. Cuando la legislación positiva declara la no punibilidad del aborto y acoge las indicaciones terapéutica, ética y eugenésica, está configurando — como excusas absolutorias o causas de exención de pena- los acontecimientos colectivos que la oferta política vincula al cambio cultural y refuerza con un espeso aparato retórico.

La doctrina tecnicojurídica del delito no permite hablar, en tal caso, de fórmulas despenalizadoras del aborto, que sólo se darían si - de modo aberrante - se rehusara a la vida humana el carácter de bien jurídicamente protegido. Despenalizar una figura delictiva es expulsarla del catalogo de ilícitos del texto punitivo o declarar, sin reservas ni lugar a dudas, que una conducta - constitutiva de delito hasta entonces - ha dejado de serlo, porque así lo prefiere la libertad decisoria del legislador.

La supuesta despenalización del aborto acusa ese defecto, aunque una diversión nominalista se empeñe en defender lo descabellado de la tesis y degrade el bien-vida a la categoría de un valor neutral que no puede desnaturalizarse por completo. Ello entraña una contradicción en los términos, porque la idea de valor vital - a que se acude para designar la animación mutua de las realidades de los mundos del ser y del valor - se muestra indivisible y enseña que, por definición, la integridad de la vida -igual a sí misma y siempre tal- no tolera desmerecimientos ni recortes. Las mal llamadas técnicas despenalizadoras no borran la fisonomía delictiva de las variantes de interrupción del embarazo que introducen. Innovan excusas absolutorias consistentes en la exención de pena que el legislador establece por razones individuales o sociales que juzga bastantes para reaccionar así.

La despenalización - relativa a cualquiera de esas indicacionespugna con la inspiración que, según el art. 1.1 CE, emana del sistema 
de valores superiores del ordenamiento jurídico. Todos ellos limitan el albedrío del legislador que artificiosamente ensancha o reduce el campo cultural o las fronteras naturales de la tutela penal. Mientras que la tipificación de los denominados delitos artificiales se debe al margen de discrecionalidad que facilita el ingreso de ciertos bienes y/o valores a la esfera protectora del Derecho Penal, el elenco de los delitos naturales - comprensivo, entre otras, de las figuras clásicas de los delitos contra la vida de las personas físicas- forma parte del acervo de normas de cultura con que la conciencia colectiva veda las iniciativas legales de signo contrario. La norma de cultura central — que aclama y enaltece el respeto del derecho a la vida - acusa la desprotección de un bien indispensable para que los valores superiores del ordenamiento jurídico garanticen la dimensión antropocéntrica de la sociedad pluralista y de los grupos a que ha dado cabida.

Es claro que, además de la tutela del derecho a la vida durante el embarazo, la suerte de un interés social -inherente al derecho a la protección de la salud individual y colectiva- depende del tino de estas reflexiones.

\section{Protección y recuperación del medio ambiente}

El discurso del pensamiento económico sobre el fenómeno de la degradación del medio ambiente precedió a la reflexión de los juristas, aunque - yendo en busca del tiempo perdido - el Derecho, que ha ganado terreno, se apodera de una materia cuyos problemas quiere abordar exhaustivamente.

Los aspectos indemnizatorios de los daños causados por los atentados contra el medio ambiente suscitaban reparos de monta, pues las violaciones del derecho a la protección de la salud afectaban a bienes cuya titularidad no era de inequívoca determinación a la luz de los tradicionales criterios del Derecho Civil. El otro — paciente del daño que el art. 1.902 C.c. declara resarcible a título de culpa o negligenciafue siempre, sin duda ni perplejidad, la persona - física o jurídica- de cuyo patrimonio formaba parte el bien o derecho lesionado. Las pautas del régimen de la responsabilidad extracontractual no estaban pensadas para afrontar los problemas de unos grupos o colectividades - más o menos concretos - de perjudicados, cuya conexión con el objeto del derecho subjetivo era costosamente perceptible. Tampoco se podía reconocer la legitimación activa - poder de conducción procesal para lograr una respuesta judicial, favorable o adversa, a la pretensión indemnizatoria- de quienes no eran portadores de un interés tutelado, 
directa y explícitamente, por el Derecho objetivo. De ahí, la revisión del planteamiento clásico y la exigencia de inventar — descubriéndolas inteligentemente- soluciones originales y efectivas.

Presupuestas la unidad e indivisibilidad del fenómeno que engendra estas insuficiencias, los problemas de individualización del sujeto perjudicado y las garantías procesales de su indemnidad no se ciñen a los casos de degradación del medio ambiente y se propagan a situaciones - propias de inimaginables avances tecnológicos- que suman otros interrogantes. Ello aconseja un tratamiento cuya solvencia disipe las brumas de sus horizontes y procure los instrumentos válidos para fijar el mejor de los cuerpos de doctrina posibles.

La unidad metodológica revela el carácter interdisciplinar de las técnicas analíticas y lo valioso de los instrumentos empleados. Evaluar el coste de una construcción jurídica y pronunciarse sobre su pertinencia, compete a las operaciones del análisis económico del Derecho que subyacen a la lectura enfática de los pasajes del cap. 3. ${ }^{\circ}$, tít. I CE. La referencia de su rotulación a la política económica y el silencio de los principios -incluso de los arts. 43.1 y $45.1 \mathrm{CE}$ - sobre sus particularidades, dan a entender que, si el designio economicista no es parte de la regulación y sí de la rúbrica que inicia ese conjunto, la voluntad del constituyente se compromete con una idea sugestiva. La - ya apuntada- de que la predilección de los principios rectores por el cumplimiento de los fines de todas y cada una de las políticas sociales, se predica con la misma extensión e intensidad - es decir, inexorable e indisociablemente- de las medidas de política económica que hacen falta para alcanzar aquellos objetivos.

Apelando al auxilio de ciertos sectores del ordenamiento jurídico, la unidad de investigación se aprovecha de las contribuciones técnicas del Derecho Público y el Derecho Privado, y de las novedades que las adquisiciones procesales proyectan sobre la dimensión - académica y polémica - de estos pormenores. La constancia de las realidades sociales - pues, no en vano, la protección del medio ambiente depende de una demanda de bienestar en que el concepto de calidad de vida prima sobre el de su nivel o cantidad - exige que la legislación civil cuide de los bienes insuficientemente atendidos por los recursos anacrónicos del derecho de propiedad privada. El legislador penal es sabedor de que, no menos que de los bienes materiales en sentido estricto, debe ocuparse de la totalidad difusa en que reside la disposición del medio ambiente. La legislación procesal ha de regular el derecho de acceso a la jurisdicción y completar la efectiva tutela judicial de los derechos e intereses legítimos que giran en torno a una nueva constelación de circunstancias. 
Hay que elogiar la solución a que el constituyente ha llegado para remediar las carencias de que se hace mérito. A la defensa y restauración del medio ambiente no se accede sin cumplir un deber general de abstención, cuyo perfil actualizado revive la prohibición — estampada en el art. 1.902 C.c. - de dañar a terceros y reintroduce el antecedente de la obligación pasiva universal. La indispensable solidaridad colectiva - a que el art. 45.2 CE alude de pasada - restaura la figura que los yusprivatistas aplicaron a la actitud de quienes, más o menos cercanos al círculo del sujeto titular de un derecho absoluto, debían evitar cuantas acciones le vulnerasen o pusieran en riesgo de lesión. La debilitación o la falta de solidaridad colectiva desencadena el ciclo de eficiencia causal de las acciones u omisiones que degradan el valor del medio ambiente o escatiman a los poderes públicos la contribución indispensable para su defensa.

Hay un paralelismo evidente entre la que el art. 45.2 CE llama utilización racional de los recursos naturales y el deber de atención y cuidado cuyo reverso es la culpa o negligencia que el art. 1.902 C.c. convierte en título de indemnización. Ahora bien, se usa de una reinterpretación que - a la luz de la teoría del riesgo- invierte equitativamente la carga de la prueba y, conforme a los arts. 9.2 CE y 3.2 C.c., impone al agente dañoso la demostración de que las consecuencias producidas se debieron a la ocurrencia de un evento externo o a la cocausalidad del perjudicado. Utilizar racionalmente - ¿ ejercitando sin abuso las facultades posesorias? - es cooperar con la dosis de esmero y animación sicológica necesarias para preservar la indemnidad del medio ambiente amenazado. Ello obliga a abstenerse de crear más riesgos que los que una diligencia normal puede evitar, y condena las agravaciones procedentes de un manejo precipitado o abusivo de los elementos ambientales.

El art. 45.1 CE proclama la responsabilidad de quienes, utilizando irracionalmente los recursos naturales e incumpliendo sus deberes de solidaridad, causan un daño - de cualquier especie- que deja indefenso al medio ambiente, lo degrada o impide su recuperación. Sin perjuicio de la recepción de las nuevas responsabilidades penales y administrativas, el régimen propuesto para el resarcimiento del daño diluye las objeciones tecnicojurídicas que impedían abordar los más arduos aspectos del problema.

$\mathrm{El}$ art. 45.1 CE reitera el pronombre indefinido todos — del que se sirven multívocamente otros preceptos de la carta política- para designar a las comunidades que, como portadoras de intereses difusos, asumen la misión de defender y promover la conservación del medio ambiente. El concepto de interés difuso emerge a mitad de camino en- 
tre el interés general -equivalente al bien común que reclama la atención de la política legislativa- y los intereses particulares que, con o sin el ropaje jurídico del derecho subjetivo, forman parte del patrimonio personal. Si el art. 45.1 CE admite la reparación del daño, es porque el infractor está obligado a aplicar una parte de su activo patrimonial - a saber, la suma de resarcimiento- a compensar el perjuicio sufrido por un grupo subjetivamente indeterminado y, no obstante, susceptible de una individualización que facilite el destino de la indemnización adeudada.

El constituyente no elige la solución del art. 45.1 CE por veleidades de la moda, ni quiere reiterar, por superabundante, la que, para el Derecho Privado, es de antigua doctrina fijada. Prefiere eliminar los obstáculos tecnicojurídicos que entorpecen la protección eficaz del medio ambiente y no recata la esperanza puesta en que las operaciones del esfuerzo transformador repercutan positivamente en tan apreciable circunstancia.

\section{Experimentación en la persona}

La protección de la salud se relaciona de inmediato con los problemas de la experimentación en la persona humana. Por tal se entienden las actividades dirigidas al avance científico de las adquisiciones de la Medicina e independientes de un plazo predeterminado para comprobar - gracias a la reiteración de pruebas efectuadas en la persona del sujeto-objeto de las medidas aplicables - la virtud curativa de tratamientos nuevos. Es claro que, so pena de perder su relieve y su fisonomía, esas medidas regeneran los elementos del concepto de salud y reducen sus componentes de agresión intrínsecos y extrínsecos. No se proponen fomentar las tentativas encaminadas a constatar el resultado de ensayos economicistas, belicistas o incompatibles con el respeto debido a la dignidad personal. El contenido esencial del derecho en cuestión - que, pese al designio de regular solamente principios, reconoce realmente el art. 43.1 CE- puede verse afectado por los tratamientos empeñados en acreditar el éxito de los productos curativos o de las terapias que se han ensayado.

Hay que intentar, por encima de todo, la individualización de los intereses que han de armonizarse. Si el paciente de la experimentación se beneficia del derecho a la supervivencia que le otorga el art. $15 \mathrm{CE}$, no es menos cierto que, sin perjuicio de la cosificación (i?) a que se arriesga su persona, tiene derecho a mejorar mediante un tratamiento regido por obligaciones — de medios o de simple activi- 
dad- cuya frustración, más o menos intensa, no es imputable a los agentes curativos que usen de la diligencia exigible para evitar el fallecimiento del enfermo. Al alegato circular de la irresponsabilidad así avalada, se contesta que, si no se cuenta con certidumbre y solvencia para comenzar la experimentación, parece aventurado hacerlo al precio de unas consecuencias cuyos inconvenientes se eluden mediante una fórmula general que - trasladada a los problemas del derecho a la vida y la protección de la salud- despierta recelos y actitudes escépticas.

No puede perderse de vista lo atractivo de la defensa del progreso científico - protegido en el art. 20.1 $b \mathrm{CE}$ - que, aunque produce un beneficio compensado colectivamente con el sacrificio del interés individual del paciente, recaba esfuerzos de contribución que alivien los riesgos del experimento.

Desde un punto de vista tecnicojurídico, el requisito del consentimiento del paciente no debe sobrevalorarse ni reducirse a reglas harto formalistas. La estadística prueba que estos episodios se superan acudiendo a la solución del estado de necesidad o invocando una circunstancia eximente - afín a la no exigibilidad de otra conducta- que deriva de los actos concluyentes del enfermo. Este se halla dispuesto a soportar las peripecias de un régimen de curación que, a juzgar por su conformidad inequívoca, constituye aliciente bastante para aceptar el remedio ofrecido y mantener la esperanza razonable de que mejorará su estado de salud.

El consentimiento del enfermo mental no se equipara, por hipótesis, a la capacidad plena de entender y de querer. Dimana de una voluntad fundamental cuyos juicios de aproximación permiten representarse un estado de cosas asimilado con probabilidad que descarta la vulneración de los derechos innatos del sujeto. La dinámica del consentimiento no se agota en su sustitución por la voluntad judicial que aprueba el sometimiento al acto de experimentación y - sin perjuicio de la tutela deferida por el art. 24.1 CE- aconseja establecer controles que armonicen las demandas de la moderna estructura de la sanidad y la socialización de la medicina.

\section{Valores de orientación del Derecho sanitario}

La organización de la reforma sanitaria ha de integrar los valores del respeto a la dignidad personal, que el art. 10.1 CE declara preeminente, en un proyecto participativo que - apoyado por los grupos sociales significativos que, de pasada, menciona el art. 20.2 CE- aborde 
los problemas que, por quién sabe qué motivaciones confusas, aguardan una satisfactoria solución.

La importancia de la reforma del ordenamiento jurídico de la protección de la salud mental se explica por sus nexos con el valor de la salud básica, con la necesidad de mantener indemne la reserva de salud y con la autorrealización a que se extiende la promesa del art. 49 CE. Si la salud es, ante todo, ausencia de enfermedad, su integridad lleva consigo la dosis de salud mental que permite conservar la conciencia de esa condición. Si el nivel superior de su concepto coincide con el pleno equilibrio del ser personal, su intangibilidad rechaza un detrimento de la salud mental que puede aminorarla.

La axiología de ese sector del ordenamiento jurídico obliga a diagnosticar el momento en que el Derecho constituido se encuentra y justifica las transformaciones necesarias. De la apreciación y cotejo de los ritmos temporales de la evolución legislativa depende el decidir si, pese a lo antiguo de la regulación, ésta sigue siendo aceptable - lo cual no ha de excluirse - o si se trata de una ordenación obsoleta, incompatible con las demandas de la moderna sociedad y, lo que es más grave, dominada por prejuicios de segregación que los países más civilizados no han acertado a suprimir.

Hay también que estimar, como aspecto estadístico de relieve, la proporción de enfermos que, al planificarse y emprenderse la reforma, están sometidos a tratamiento voluntario, pues -amén de la importancia de este dato para las operaciones de análisis económico del Derecho- la distancia entre la eficacia actual de las acciones sanitarias y el adelanto de los cambios previstos, es un elemento de la realidad social - que la política legislativa no puede desdeñar- y un punto de partida para ponderar las diferencias entre el estado de cosas de entonces y el que, según el art. 3.1 C.c., le sucede a tenor del criterio evolutivo de interpretación judicial.

Es importante percatarse de si las novedades proyectadas trazan una línea de fuerza original o sólo robustecen las bases de un movimiento de reforma iniciado, cuya estructura debe subsistir para evitar injerencias que atenten contra la integridad del sistema y acaso destruyan su equilibrio.

Un Derecho de Gentes protector de la salud mental se endereza a objetivos inseparables de su identidad y susceptibles de una regulación a corto o medio plazo. Las reminiscencias de un tratamiento antifuncional o dividido ceden ante los criterios colectivos y sistemáticos que se aplican en instituciones especializadas. El proceso de reinserción social de los enfermos mentales se completa con soluciones encaminadas a disminuir el número de afectados crónicos y favorecer el retorno de los 
recuperados a los grupos sociales de origen. Frente a los obstáculos que, perpetuando situaciones de desigualdad, demoran la atención de las enfermedades mentales, hay que asentir a técnicas de diagnóstico rápido y terapias aceleradoras de la reintegración.

Es inaplazable la protección comunitaria que, ante el riesgo del grupo de enfermos peligrosos, armonice la paz social con el todo de los fines expuestos, para que - conforme a los arts. 9.2 y $45.2 \mathrm{CE}-$ la suma del esfuerzo transformador de los poderes públicos y la indispensable solidaridad colectiva culmine el proceso de protección que se pone a cargo del Derecho.

La técnica legislativa -inspirada en esos valores culturales y en sus normas de organización - se alimenta de varios postulados. Los servicios relativos al tratamiento de enfermos mentales han de integrar los servicios médicos generales para no frustrar el tratamiento racionalizado de la enfermedad y evitar que revivan las situaciones discriminatorias que se pretende superar. Hay que convertir en Derecho objetivo $\mathrm{y}$, si es posible, codificar ágilmente - teniendo en cuenta ese Derecho de los pueblos y los principios constitucionales que son eco suyo- el elenco de derechos individuales del enfermo, como tal y como ciudadano. Hay que implantar un régimen educativo y unas garantías - del enfermo y de sus familiares - que permitan informar verazmente sobre los instrumentos jurídicos de que se dispone. A la satisfacción de estas demandas, se añadirán, en cada situación particular, cuantas medidas doten al paciente de un tratamiento sanitario completo - apto para eliminar los males que le aquejan-y conveniente a los valores de su dignidad personal.

Conforme a los arts. 24.1 y $105 c$ CE, el procedimiento relativo al tratamiento obligatorio de los enfermos síquicos debe garantizar su audiencia, si es razonablemente necesaria, y preservar sus derechos y libertades mediante una tutela judicial cuya efectividad se extienda a todos los intereses afectados por dicha circunstancia.

La vieja inclinación represiva - propensa a expulsar de la comunidad a los enfermos cuya condición antisocial se presumía sin templanza ni prueba en contrario- se corrige según las sugerencias del Derecho Penal humanitario y se sustituye por operaciones reconstructivas de la personalidad del enfermo. A la perspectiva - técnicamente descalificada y precaria - de un tratamiento irregular y disperso, sucede un régimen comunitario racional y avalado por el éxito de sus experiencias. La degradación de los enfermos mentales - hasta entonces sujetos de un género diverso - da paso a las aspiraciones de que su personalidad disponga de un espacio habitable en el todo de la familia humana. En vez del tratamiento jurídico viciado por la dificultad de aprovechar 
fórmulas normativas residuales, se erige una organización — de nueva planta - resuelta a promover el éxito social de la moderna noción de salud pública.

\section{Orientación bibliográfica}

ALESSI: L’amministrazione sanitaria, Milán, 1967.

ANGELICI: Principi di diritto sanitario, Milán, 1963.

BuSNELLI y BRESCIA: Il diritto alla salute, Bolonia, 1979.

GRABITZ: Freiheit und Verfassungrecht, Tubinga, 1976.

HeRZlich: Santé et maladie, París, 1969.

LEGA: Il diritto alla salute in un sistema di sicurezza sociale, Turín, 1952.

LUCAS VERDÚ: El sentimiento constitucional, Madrid, 1985.

MasLow: El hombre autorrealizado, trad. de RIBE, Barcelona, 1987.

MEAD y otros: Societés, traditions et technologie, París, 1954.

Modugno: Trattamenti sanitari non obbligatori e Costituzione, Milán, 1982.

PAтti: La tutela civile dell' ambiente, Padua, 1979.

PeZzINI: Diritto alla salute: profili costituzionali, Milán, 1983.

Pızzi: Malattie mentali e trattamenti sanitari, Milán, 1978.

SALVI: Le inmissioni industriali, Milán, 1979.

SCHRAMM: Grundrechts und ihre verfassungsrechtliche Absicherung, BerlinBonn-Munchen, 1977.

SigERIST: Civilization and disease, Chicago, 1943.

ZORRILLA: El recurso de inconstitucionalidad contra la Ley del Aborto, Bilbao, 1985.

Dificultad politicolegislativa de una ordenación sanitaria, Madrid, 1986.

\section{Abreviaturas y siglas}

art.: artículo.

cap.: capítulo.

C.c.: Código Civil español de 24.7.(8)89.

CE: Constitución española de 27.12.(9)78.

dec.: decisión

Pr.: Preámbulo.

sec.: sección.

tít.: título.

VCTR: Versión Consolidada del Tratado de Roma de 25.3.57, modificada por el Tratado de Amsterdam de 2.10.97. 